\title{
CARACTERIZAÇÃO PARCIAL DE PROTEASES POR Aspergillus tamarii URM4634 POR FERMENTAÇÃO EM ESTADO SÓLIDO (FES)
}

\author{
O. S. da SILVA ${ }^{1}$, T. N. S. LAURENTINO ${ }^{2}$, R. L. de OLIVEIRA ${ }^{2}$, T. S. PORTO ${ }^{1,2}$ \\ ${ }^{1}$ Universidade Federal Rural de Pernambuco, Departamento de Morfologia e Fisiologia \\ Animal \\ ${ }^{2}$ Universidade Federal Rural de Pernambuco, Unidade Acadêmica de Garanhuns \\ E-mail para contato: portots@yahoo.com.br
}

\begin{abstract}
RESUMO - As proteases são um grupo de enzimas muito importantes na indústria. O objetivo desse estudo foi caracterizar parcialmente as proteases produzidas por Aspergillus tamarii URM4634 em Fermentação em Estado Sólido, utilizando substrato Fibra de Trigo. Na caracterização foi verificado $\mathrm{pH}$ ótimo e temperatura e estabilidade à temperatura e ao $\mathrm{pH}$. Para os estudos de $\mathrm{pH}$ foram utilizados tampões a 0,2M Citrato-Fosfato, Tris- $\mathrm{HCl}$ e Glicina$\mathrm{NaOH}$ na faixa de $\mathrm{pH}$ de 5,0 a 11,0, com azocaseína 1\%. Quanto aos estudos de temperatura foram avaliadas diferentes temperaturas $\left(5\right.$ a $\left.80^{\circ} \mathrm{C}\right) . \mathrm{O} \mathrm{pH}$ ótimo da protease foi no Tris- $\mathrm{HCl} \mathrm{pH} 8,0$. A enzima foi estável em $\mathrm{pH} 8,5$ mantendo 95,6\% de atividade. A temperatura ótima da protease foi a $40^{\circ} \mathrm{C}$. Quanto à estabilidade à temperatura, apresentou $97 \%$ de atividade residual a $40^{\circ} \mathrm{C}$ após 180 minutos. A protease de A. tamariiapresentou com potencial para aplicação na indústria, pois exibiu características enzimáticas adequadas e não demandam temperaturas e $\mathrm{pH}$ elevados.
\end{abstract}

\section{INTRODUÇÃO}

A produção de enzimas proteolíticas pelos micro-organismos se tornou uma alternativa muito atraente para aplicações específicas do ponto de vista industrial, sendo utilizadas em diversas atividades como no processamento de alimentos, bebidas, formulação de detergentes, processamento de couro e pele, amaciamento de carnes, formulação de medicamentos, indústria têxtil, entre outros, devido às recentes melhorias nas técnicas de produção e purificação (Koblitz, 2008).

As proteases, enzimas responsáveis pela hidrólise de proteínas (Kranthi; Rao; Jaganmohan, 2012), compreendem um grupo de enzimas muito importantes na indústria, o que corresponde a cerca de 60\% (Akcan; Uyar, 2011) a 65\% (Yin; Chou; Jiang, 2013) das enzimas comercializadas.

Essas enzimas podem ser obtidas de várias fontes biológicas como vegetais, animais e micro-organismos (Mikhailova, 2011). Todavia, os micro-organismos são considerados a melhor fonte enzimática, devido às suas propriedades bioquímicas e seu elevado rendimento, além de produzirem enzimas extracelulares importantes para a degradação e transporte de nutrientes para a célula. Dentre os fungos estudados, destaca-se o gênero Aspergillus, que 
apresenta grande aplicabilidade na produção de enzimas para a indústria (Marquartet al. 2002).

A produção de enzimas através de micro-organismos se dá por processos de fermentação, esses podem ser de dois tipos: a fermentação submersa (FS) e a fermentação em Estado Sólido (FES). Na FES, o meio de cultura é composto de substratos sólidos, atuando como fonte de carbono e energia, e apresenta ausência total ou quase total de água livre, o que faz com que essa condição de crescimento tente se aproximar do habitat natural do fungo. Nesse tipo de processo são utilizados produtos ou subprodutos oriundos da agroindústria como substrato, o que proporciona uma vantagem econômica, uma vez que há o aproveitamento de resíduos que seriam possivelmente descartados (Pandeyet al. 2001; Orlandelliet al. 2012).

O presente trabalho teve como objetivo a caracterização parcial de proteases produzidas pela linhagem fúngica Aspergillus tamarii URM 4634 por fermentação em estado sólido.

\section{METODOLOGIA}

\subsection{Micro-organismo}

O Micro-organismo Aspergillus tamarii URM4634 foi obtido da coleção de culturas da Micoteca URM, do Departamento de Micologia, do Centro de Ciências Biológicas, da Universidade Federal de Pernambuco e mantidos em tubos de ensaios inclinados contendo o meio Czapek Agar Dox e feito repique para manutenção a cada 28 diase incubados a $30^{\circ} \mathrm{C}$.

\subsection{Substrato para a Fermentação}

O substrato utilizado para a Fermentação em Estado Sólido (FES) foi obtido no comércio local. O substrato, farelo de trigo, foi padronizado numa granulometria entre $0,5-$ $2,0 \mathrm{~mm}$ e secos em estufa a $65^{\circ} \mathrm{C}$ e em seguida armazenado em recipientes hermeticamente fechados.

\subsection{Produção de Proteases por FES}

O micro-organismo foi inoculado em frascos Erlenmeyer $125 \mathrm{~mL}$, contendo o meio Czapek, incubados a $30^{\circ} \mathrm{C}$ por 7 dias até ocorrer esporulação. Os esporos foram coletados com a adição de solução $\mathrm{NaCl}$ 0,9\% (p/v) e Tween 80 0,01\% (v/v) previamente esterilizados. A contagem dos esporos foi realizada em câmara de Neubauer, o inóculo foi padronizado para a concentração final de $10^{7}$ esporos/mL. Por conseguinte, inoculados nos frascos Erlenmeyer de $125 \mathrm{~mL}$ contendo $5 \mathrm{~g}$ de fibra de trigo, autoclavados a $121^{\circ} \mathrm{C}$ por 20 minutos, a $40 \%$ de umidade e incubados a $30^{\circ} \mathrm{C}$ em B.O.D por 72 horas para a produção de proteases em FES. Ao fim da fermentação, foi adicionado 7,5mL/g de tampão Fosfato de Sódio 0,1M pH 7,0 ao fermentado e homogeneizado na mesa agitadora por 2 horas para extração da enzima. Em seguida, o substrato foi macerado por1 minuto e filtrado. Os sólidos foram removidos por centrifugação a $5000 \mathrm{rpm}$ por 15 minutos a $4^{\circ} \mathrm{C}$ e o sobrenadante foi coletado para ensaios analíticos. 


\subsection{Determinações Analíticas}

\subsubsection{Atividade Proteásica}

A atividade proteásica foi determinada pelo método de Ginther (1979), tendo como substrato a Azocaseína (Sigma-Aldrich, St Louis, EUA) a 1\% (p/v), solubilizada em tampão Tris-HCl, 0,2M, pH 7,2, a temperatura ambiente; $10^{-3} \mathrm{M} \mathrm{CaCl} 2$. A mistura de reação foi composta de $0,15 \mathrm{~mL}$ de extrato enzimático e $0,25 \mathrm{~mL}$ de Azocaseína 1\%, incubados por 1 hora a $25^{\circ} \mathrm{C}$. Após este período, a reação foi interrompida com adição de $1 \mathrm{~mL}$ de TCA $10 \%$ $(\mathrm{p} / \mathrm{v})$. As amostras foram centrifugadas a $3.000 \times \mathrm{g}$ por 20 minutos, e $0,8 \mathrm{~mL}$ do sobrenadante foi adicionado a $0,2 \mathrm{~mL}$ de $\mathrm{NaOH} 1,8 \mathrm{~N}$. Uma unidade de atividade da protease foi definida como sendo a quantidade de enzima requerida para produzir uma variação de absorbânciaigual a 0,1 em 1 hora, a 420nm, sendo expressa em U/mL.

\subsubsection{Determinação de Proteínas}

Para determinar as proteínas totais, foi utilizado o método de Bradford (1976), que utiliza ComassieBrilhant Blue G-250 como corante e Albumina de Soro Bovino(BSA) como padrão.

\subsection{Caracterização da Protease}

\subsubsection{Efeitos do pH na atividade enzimática e Estabilidade ao pH}

$\mathrm{O}$ pH ótimo para atividade enzimática para protease foi determinado utilizando diferentes tampões a 0,2M: Citrato-Fosfato ( $\mathrm{pH} 5,0-7,0)$; Tris- $\mathrm{HCl}(\mathrm{pH} 7,0-8,5)$; e Glicina$\mathrm{NaOH}(\mathrm{pH} 8,5-11,0)$. A determinação da atividade proteásica foi realizada como descrito no item 2.4.1. A estabilidade ao $\mathrm{pH}$ foi verificada submetendo a enzima aos tampões descritos anteriormente e incubados a $5^{\circ} \mathrm{C}$. Alíquotas foram retiradas para determinar a atividade proteásica em intervalos de tempo $0,4 \mathrm{~h}, 8 \mathrm{~h}$ e $24 \mathrm{~h}$.

\subsubsection{Efeitos da temperatura na atividade enzimática e Estabilidade à temperatura}

A temperatura ótima foi determinada através da realização da atividade proteásica em temperaturas que variaram de $5 \mathrm{a} 80^{\circ} \mathrm{C}$. Para avaliar a estabilidade à temperatura, o extrato enzimático foi submetido previamente a diferentes temperaturas de 5 a $90^{\circ} \mathrm{C}$, posteriormente alíquotas foram retiradas a cada 60 minutos para determinar atividade proteásica em intervalos de tempos de 0 a 180 minutos.

\section{RESULTADOS E DISCUSSÕES}

A protease foi produzida com atividades máximas de 404,67 U/mL a partir do fungo Aspergillus tamarii URM4634, usando 5g de farelo de trigo como substrato, umidade de $40 \%$ após 72 horas de incubação, mostrando que a Fermentação em Estado Sólido é efetiva na produção de proteases por A. tamarii URM4634. 


\subsection{Efeito do pH na atividade enzimática e Estabilidade ao pH}

$\mathrm{O}$ efeito do $\mathrm{pH}$ na atividade enzimática da protease produzida pelo Aspergillus tamarii URM4634 foi observadoem pH ótimo de 8,0, como mostra a Figura 1, em tampão Tris- $\mathrm{HCl}$ e sua menor atividade em pH 5,0 no tampão citrato-fosfato. $\mathrm{O}$ mesmo $\mathrm{pH}$ ótimo foi encontrado em uma protease alcalina produzida por Aspergillus nidulans HA-10(Charles et al., 2008), utilizando meio sintético para o crescimento do micro-organismo.

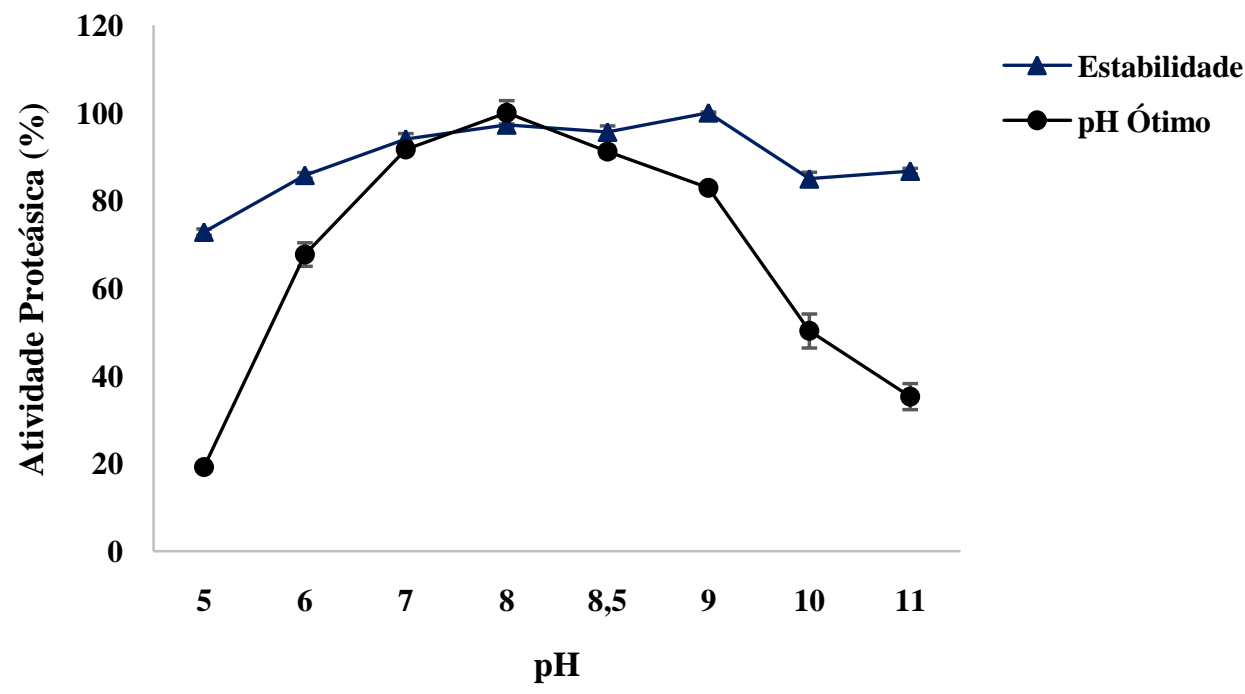

Figura 1 - Curva de $\mathrm{pH}$ ótimo e estabilidade da protease produzida por Aspergillus tamarii URM4634 em diferentes tampões por 24 horas de reação.

Pesquisa semelhante com o fungo termófilo Myceliophthoraspapresentou $\mathrm{pH}$ ótimo em 9,0 e 1,78 U/mL de proteases quando crescido em FES. Por outro lado, o mesmo microorganismo crescido em Fermentação Submersa (FS) teve seu pH ótimo em 7,0 e 0,38U/mL de atividade proteásica (Zanphorlin et al., 2010).

A estabilidade ao $\mathrm{pH}$ da enzima é importante para a caracterização enzimática, antes de ser comercializada. A protease produzida pelo Aspergillus tamarii URM4634 mostrou estabilidade ao $\mathrm{pH} \mathrm{8,0} \mathrm{com} \mathrm{97,24 \%} \mathrm{de} \mathrm{atividade} \mathrm{residual,} \mathrm{permanecendo} \mathrm{ativa} \mathrm{durante} \mathrm{todos}$ os pHs testados, chegando com 24 horas de ensaio com atividade residual acima de $66 \%$ e 97\% em seu pH ótimo.

Essa estabilidade ao $\mathrm{pH}$ da protease de A. tamarii URM4634 demonstra o seu potencial para possíveis aplicações industriais, por apresentar propriedades alcalíficas exibidas por proteases de A. tamarii URM4634, que podem ser empregadas nas indústrias alimentícias, no processamento de couro, detergentes e farmacêutico (Zanphorlin et al., 2010). Resultados similares foram reportados para proteases alcalinas de Aspergillus niger (pH8,0)(Devi, 2008), Aspergillus niger $(\mathrm{pH}$ 8,5) (Dubey et al., 2010) e Aspergillus parasiticus (pH8,0) (Tunga; Shrivastava; Banerjee, 2003) os quais apresentaram estabilidade ao $\mathrm{pH}$ na faixa de 6,0 - 12,0, corroborando com os dados desse trabalho. 


\subsection{Efeito da temperatura ótima e a Estabilidade na atividade enzimática}

A produção máxima de protease foi obtida na temperatura ótima de $40^{\circ} \mathrm{C}$, sendo que a atividade decaiu após $50^{\circ} \mathrm{C}$, como mostra a Figura 2, a enzima apresentou $100 \%$ e $97 \%$ de sua atividade, máxima, respectivamente.

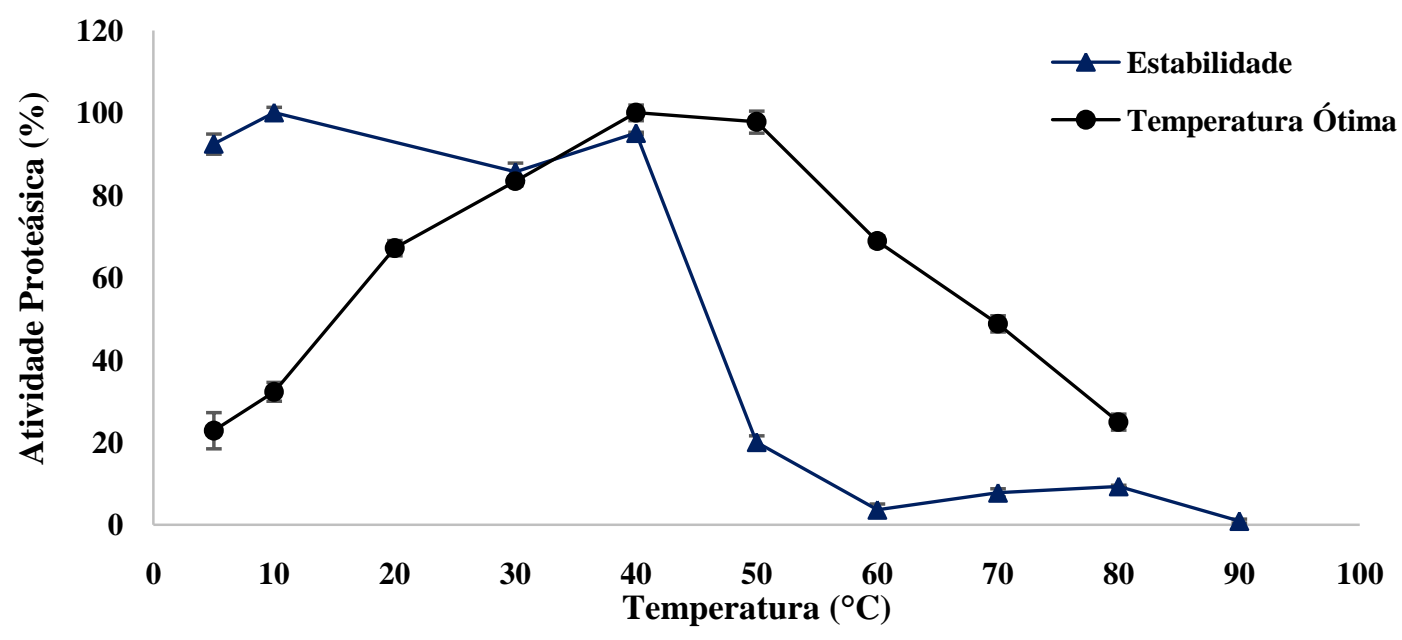

Figura 2 - Curva de temperatura ótima da protease e estabilidade da protease produzida por Aspergillus tamarii URM4634 em diferentes temperaturas por 180 minutos de reação.

Tunga (2003) encontrou a mesma temperatura ótima para a caracterização proteásica de Aspergillus parasiticus. Este valor foi similar aos encontrados para proteases de Aspergillus flavus, utilizando diferentes sementes oleaginosas como substrato (Kranthi; Rao; Jaganmohan, 2012). No entanto, uma temperatura ótima a $60^{\circ} \mathrm{C}$ foi relatada na produção de proteases por Aspergillus fumigatus(Hernández-Martínez et al., 2011). De acordo com esses autores, a protease apresentou $60 \%$ de atividade residual a $64^{\circ} \mathrm{C}$. Quanto ao Aspergillus tamarii URM4634 apresentou mais de $68 \%$ de atividade residual quando comparada a mesma temperatura descrita por Hernández-Martínez et al. (2011).

A enzima se mostrou estável à temperatura, mantendo sua atividade residual acima de $90 \%$ a $40^{\circ} \mathrm{C}$ e decaindo na temperatura de $50^{\circ} \mathrm{C}$ com sua atividade residual de $20 \%$, apresentando atividade proteásica de $308 \mathrm{U} / \mathrm{mL}$ e $65 \mathrm{U} / \mathrm{mL}$, respectivamente, aos 180 minutos de ensaio. Diferente do visto, a protease produzida pelo Aspergillus parasiticus, teve sua atividade reduzida a $50^{\circ} \mathrm{C}$ após 60 minutos(Tunga; Shrivastava; Banerjee, 2003).

\section{CONCLUSÕES}

A Fermentação em Estado Sólido mostrou ser efetiva na produção de proteases por Aspergillus tamarii URM4634, apresentando ótimas atividades enzimáticas em faixa ampla de $\mathrm{pH}$ e temperaturas favoráveis para aplicação nos processos industriais. A protease produzida tem grande potencial nas indústrias alimentícias, detergentes, farmacêutica e couro. 


\section{REFERÊNCIAS}

AKCAN, N.; UYAR, F. Production of extracellular alkaline protease from Bacillus subtilis RSKK96 with solid state fermentation. Eur. Asian. J. Biosci., v. 72, n. July, p. 64-72, 2011.

BRADFORD, M. M. A rapid and sensitive method for the quantitation of microgram quantities of protein utilizing the principle of protein-dye binding. Analy. bioch., v. 72, p. 248-54, 7 maio. 1976.

CHARLES, P. et al. Purification, characterization and crystallization of an extracellular alkaline protease from Aspergillus nidulans HA-10. J. Bas. Microbiology, v. 48, n. 5, p. $347-$ 52, out. 2008.

DEVI, M. Purification, characterization of alkaline protease enzyme from native isolate Aspergillus niger and its compatibility with commercial detergents. Ind.J.Scien.Techn. v. 1, n. 7, p. 1-6, 2008.

DUBEY, R. et al. Isolation, Production, Purification, Assay and Characterization of Alkaline Protease Enzyme from Aspergillus niger and its Compatibility with Commercial Detergents. Devel. Micro. and Mol. Bio., v. 1, n. 1, p. 75-94, 2010.

GINTHER, C. L. Sporulation and the production of serine protease and cephamycin C by Streptomyces lactamdurans. Anti. agent. and chemo., v. 15, n. 4, p. 522-6, abr. 1979.

HERNÁNDEZ-MARTÍNEZ, R. et al. Purification and characterization of a thermodynamic stable serine protease from Aspergillus fumigatus. Proc. Bioch., v. 46, n. 10, p. 2001-2006, out. 2011.

KOBLITZ, M.G.B. Bioquímica de Alimentos: Teoria e Aplicações Práticas. $1^{\mathrm{a}}$ ed. Guanabara Koogan. Rio de Janeiro. 2008.

KRANTHI, V. S.; RAO, D. M.; JAGANMOHAN, P. Production of Protease by Aspergillus flavus Through Solid State Fermentation Using Different Oil Seed Cakes. Int. J. of Micro., v. 1, p. 12-15, 2012.

MARQUART, M. M.; PAVAN, V.; GERMANI. J.C. Estudos de obtenção de proteases por Bacillus cereus em meio de proteína de soja. In: Seminário Brasileiro de Biotecnologia Enzimática, 5, Brasília Resumos, 2002.

MIKHAILOVA, R. V. Proteolytic enzymes of mycelial fungi. v. 375, n. 17, p. 47-62, 2011.

ORLANDELli, R. C.; SPECIAN, V., FELBER, A.C.; PAMPHILE, J.A.; Enzimas de interesse industrial: produção por fungos e aplicações, SaBios: Rev. Saúde e Biologia, v.7, n.3, p. 97-109, set./dez., 2012. 
PANDEY, A.; SOCCOL, C. R.; LEON, J. A. R. Solid-State fermentation in biotechnology: fundamentals and applications. New Delhi: Asiatech Publishers, 2001.

TUNGA, R.; SHRIVASTAVA, B.; BANERJEE, R. Purification and characterization of a protease from solid state cultures of Aspergillus parasiticus. Proc. Bioch., v. 38, n. 11, p. 1553-1558, jun. 2003.

YIN, L.-J.; CHOU, Y.-H.; JIANG, S.-T. Purification and Characterization of Acidic Protease from Aspergillus Oryzae BCRC 30118. J. of Mar. Scie. and Tech., v. 21, n. 1, p. 105-110, 2013.

ZANPHORLIN, L. M. et al. Production, partial characterization, and immobilization in alginate beads of an alkaline protease from a new thermophilic fungus Myceliophthora sp. $J$. of Micro. (Seoul, Korea), v. 48, n. 3, p. 331-6, jun. 2010. 